\title{
Conviviality and phatic communion?
}

\author{
Ben Rampton \\ King's College London
}

\section{Centre for Language Discourse \& Communication}

T he focus on 'unimportant' language in this collection is driven by major contemporary questions. In conditions of superdiversity, the old binaries-minority/ majority, migrant/host etc.—can no longer account for the splits and alignments emerging in globalised environments and in response, social scientists have turned their attention to informal processes, seeking new principles for social cohesion in low-key local 'conviviality' (Gilroy 2006; Vertovec 2007; Wetherell 2009). Along similar lines, commentators point to the decline of traditional party politics and look instead to social media and digital communication as new resources for grassroots mobilisation. So does the communication of apparently trivial matters really hold the seeds to social renewal, or are such ideas romantically over-inflated?

The papers provide a range of answers to questions of this kind, and I won't try to summarise their nuanced formulations, or to endorse or challenge their substantive claims. But whatever their conclusions, 'conviviality' and 'phatic communication' play a major part in the discussion; and in what follows, I will comment on how and where I think these notions are problematic or productive. My remarks are largely methodological, dwelling in particular on the challenges of working across social processes of different scale, though I will conclude with some notes on surveillance, a (substantive) issue that in sociolinguistics is often underplayed.

\section{WORKING ACROSS PROGESSES OF DIFFERENT SCALE}

The papers in this collection draw on different disciplinary backgroundsethnographic sociolinguistics, anthropology, and sociology. Small and apparently inconsequential pieces of language constitute the central theme, but they are situated in processes that are very different in scale. So we have face-to-face interaction unfolding from one moment to the next (Goebel), case study descriptions of the everyday lives and/or biographies of individuals (Velghe and Heil), and the widespread circulation of digital texts (Varis and Blommaert). The multi-scalarity of this combination of perspectives is very well justified in Blommaert and Varis's introduction:

the social structures we address... are... emergent structures characterising an evolving social order-the 
stability of which is permanently under pressure because of the diversity of people and activities that co-construct it. (...) Looking at the lowest everyday level at which such co-construction proceeds is a tactic employed by Goffman, Blumer, Cicourel and other scholars of an earlier generation, who were dissatisfied with structuralist a priori assumptions about order and stability in social systems, and who assumed that every degree of social order rests on the continuous iterative and made-meaningful enactment of characteristics of such order in everyday behaviour. We share that assumption as well as its methodological consequence: that micro-research is at once macro-research, in which a precise understanding of the macrostructures of social life can, and often does, reside in at first inspection insignificant details of people's social behaviour - such as 'unimportant language' usage (p. 7).

As Goffman (1963: 70) notes, '[w] hether we interact with strangers or intimates, we will find that the fingertips of society have reached bluntly into the contact, even here putting us in our place'. In sociolinguistics and linguistic anthropology, it is now fairly well recognised that although the conditions in which people communicate are partly local and emergent, continuously readjusted to the contingencies of action unfolding from one moment to the next, they are also infused with information, resources, expectations and experiences that originate in, circulate through, and/ or are destined for networks, media and processes that can be very different in their reach and duration (Bauman and Briggs 1990; Scollon and Scollon 2004; Blommaert 2005). As analysts, we can vary the scope of what we focus on, looking, for example, at the structure-the organisation of beginnings, middles and ends, the composition of segments etc.of very brief processes like sentences, at the structure of longer ones like genres such as the medical consultation, at the structure of the institutional networks through which medical records, for example, travel, and/or at the structure of medical careers, as well as at the links between these processual systems, which can themselves sometimes be quite stable, at least for a while. But as soon as we turn to action and meaning, we are confronted by all the contingency intrinsic to human conduct. In making sense of their situations, people process a huge range of semiotic signs and systems, bringing their understanding of all sorts of different structures to bear (material, linguistic, interactional, institutional, historical, etc.). At this point, the best that we can get from our analytic models of how processes at one, two or even three levels normally hold together, is an initial heuristic for exploring what is going on, and we are thrown into the unpredictable particularity that ethnography has taught to accept (cf. Blommaert 2013: 11-12).

This has at least two implications for the present collection.

First, if we are working across processes that differ in their duration and reach, we should not expect concepts that work reasonably well at one level/scale to continue to be useful when we shift up or down to others. It is obvious-partly because the analytic vocabularies are often different - that when a sociolinguist moves from describing the structure of T-sounds to the structure of particular communicative genres, the precise phonetic details become largely irrelevant, even though T-sounds continue to play a small but significant part in genre enactment. But there are concepts with domains of application 
that are less clear cut and that generate apparently conflicting claims when they're used at different levels. One such term is 'phatic'.

According to Crystal (2008: 360), 'phatic' refers to 'language used for establishing an atmosphere or maintaining social contact rather than exchanging information and ideas (e.g. comments on the weather, or enquiries about health)'. Leech (1981: 41) describes it as the function of 'keeping communication lines open, and keeping social relationships in good repair (talking about the weather in British culture). . . [I]t is not so much what one says, but the fact that one says it at all, that matters'. He goes on to say that phatic language 'has its parallels in public affairs. Everyone is familiar with occasions when statesmen and politicians make public utterances which are elaborate ways of saying nothing', and he gives the example of President Kennedy's inaugural speech, saying that in this speech, 'the informational function of language is reduced to a minimum' (1981: 54-55). But contrast this with Goebel's excellent microanalysis of repetition, where for example it is only when the phrase 'a place name' is repeated by Slamet in line 34 of Extract 4.3 that it is informationally redundant and appears to be primarily associated with 'ongoing relationship building efforts'. Here the account attends to the given/ new dynamic in linguistic exchange, and we are entering a delicate level of analysis where the referential and affiliative functions normally operate together in linguistic production and where it is only at very particular points in the unfolding of interaction that semantic significance recedes and the relational dimension comes to the fore. Indeed, this is very much in line with Goffman's account of interaction ritual. Ritual concernsconcerns about 'keeping social relationships in good repair'-pervade all talk (as politeness theory affirms), and it is only in a relatively limited class of conventionalised utterances that the referential dimension of language ceases to matter. ${ }^{1}$ If we were to take this powerful micro-perspective back to what Leech says about Kennedy's speech being phatic, we would have to believe that the President simply hummed or scatted through the inauguration.

The conclusion of the linguist Stephen Levinson is that functional schemes that include notions like phatic are 'of dubious utility to the pragmatist. . .: the categories are of vague application, they do not have direct empirical motivation, and there are many other rival schemes built upon slightly different lines' (1983: 41). But if we follow Levinson and reject 'phatic', what do we do when the word plays a central part in Varis and Blommaert's account of collectivity in social media? Do we adopt a foundationalist stance and say that nobody should do any social science until we have sorted out the communicative basics? Or do we accept that the clarity and stability of 'facts' always dissolve when scientific specialists get close to their object of enquiry, and learn to live with some indeterminacy?

We need to take the latter course, and welcome 'phatic' as a helpful overarching umbrella that allows Varis and Blommaert to consider how the "new online world offers numerous invitations for unthinking and rethinking semiotic truths'. Of course they treat 'phatic' as a term that requires further specification and one can retrieve the microscope to argue with how they do so. Their Zuckerberg update isn't simply visualthere is plenty of propositional content that's available to sharers, even though they may not engage with it on first encounter. $^{2}$ But judicious broad-brush characterisation of the kind sought by 
Varis and Blommaert is just as important to multilevel analysis as intensive finegrained dissection of the type achieved by Goebel.

Quantification may be an alternative or additional resource for empirical generalisation, especially with digital media, but because the contingencies that shape local sense-making are so complex, it is useful only as a rudimentary pointer. So yes, if you are studying text messaging in South Africa, you might count the number of texts that people send in Cape Town and infer from their linguistic surface that they are all about casual sociability. But Velghe's account of the perseverance and protracted battle with literacy that lies behind Linda's text messages shows just how valuable it is for empirical work to move back and forth across processes of different scale, combining linguistic analysis with participant observation, for example. This movement is not just about holding big generalisations to account with particular cases (Harris and Rampton 2009: 116-17). It also involves production of the nuanced but inevitably approximative syntheses that we call general interpretation, where terms like 'phatic'-or 'informational', or 'aesthetic'-may very well be useful. Indeed, this kind of epistemological flexibility is intrinsic to linguistic ethnography (Rampton, Maybin, and Roberts 2014), which holds that:

i. the contexts for communication should be investigated rather than assumed. Meaning takes shape within specific social relations, interactional histories and institutional regimes, produced and construed by agents with expectations and repertoires that have to be grasped ethnographically;

ii. analysis of the internal organisation of verbal (and other kinds of semiotic) data is essential to understanding its significance and position in the world. Meaning is far more than just the 'expression of ideas' and biography, identifications, stance and nuance are extensively signalled in the linguistic and textual fine-grain.

My second methodological point follows on from this: we need to be very careful with the term 'convivial'. Whether or not small talk can be characterised as convivial will very much depend on the contingencies of where, when, how, by and to whom it is produced. Heil makes this very clear in his description of educated Casamançais feeling 'appalled by unpleasant working-class small talk', even though they feel bad about 'their disdain and mockery of their neighbours' repertoires and their own lack of respect this portrayed'. If we take Goebel's list of types of action that count as small talk-giving and receiving compliments, the exchange of a joke for laughter, repetition and non-minimal responses-common experience tells us that there are lots of circumstances in which these are double-edged, sarcastic, patronising and offensive. Equally, there is nothing intrinsically convivial about 'polylanguaging' and the use of local languages you don't really know. Certainly, it can be convivial in circumstances of the kind described, for example, by Wise and Velayutham (2014)-living in the same locality, sharing the same spaces, supported both by key individuals who bring different types of people and by an intercultural habitus willing to adapt to differences. But there are plenty of studies emphasising the context-sensitivity of poly-/trans-languaging-its sensitivity to processes and relations beyond the purely linguistic - and it can often also be an expression of hostility (Hewitt 1986; Rampton 1995). In fact there are no forms of communication that are 
inalienably convivial and this simply follows from the fact that although it is a very valuable part of the puzzle, you can never get at what people mean through language alone.

But if conviviality and the practice of small talk can't be equated, does this mean that we should abandon the term as a characterisation of the social worlds in focus in this collection?

Vis-à-vis life online, my feeling is that 'phatic' is a safer term to use, for the reasons stated above. Off-line, however, in discussions of globalised urban superdiversity, the idea of 'conviviality' has gained a good deal of consensual weight, and I'd like to suggest that instead of being an adequate analytic characterisation of everyday practice, 'conviviality' describes a particular local ideology, though this needs to be very carefully contextualised in at least three ways. First, its relationship with other ideologies, both local and national, needs to be addressed. From Heil's informant Augustin Sambou, we have a clear view of conviviality's power as a reflexive representation of local life, but it is in tension with the ideologies of class influencing Aboubacar Diao and it looks distinct from the authoritative knowledge of Mandinka language and culture that Idrissa Samaté also invests in. Elsewhere, Back identifies a broadly comparable 'harmony discourse' in South London, but he examines its relationship with ideologies of black community and white flight (1996: Ch. 5), and Gilroy makes it clear that conviviality 'cannot banish conflict... and should not signify the absence of racism' (2006: 39-40).

Second, an account of convivialityas-ideology needs to rest on a description of the shared spaces and everyday projects which make ethnic and linguistic difference subsidiary to getting on with practical activity. Explicit articulations of convivial ideology may well emerge at points where ordinary routines are troubled or interrupted, but if we neglect these routines in our descriptions, we end up with an account that makes the people we associate with conviviality sound like smiley multiculturalist 'hands-across-the-divide', which they're not-they are ordinary people trying to get on with their lives (Eley 2015).

Third, the collocation of 'conviviality' and 'coping' in the papers by Heil and Velghe is very necessary to bring out this ideology's optimism-against-the-odds and subaltern political significance. After all, the varsity larks of Boris Johnson and David Cameron in the Bullingdon Club were also rather convivial and it is important not to mix them up.

\section{WHAT ABOUT SURVEILLANCE?}

I would like to close this discussant commentary on a different tack, with a few quick comments about surveillance, an issue that speaks to the questions of linkage and connection addressed in the collection, but that is rather overlooked, not only here but in the sociolinguistics of superdiversity more generally (though see Arnaut 2012).

The onset of globalised superdiversity in recent times is often linked to the early 1990s (e.g. Blommaert and Rampton 2011: 2). But this period is also associated with emergence of a huge transnational field of security professionals, which is 'larger than that of police organizations in that it includes, on one hand private corporations and organizations dealing with the control of access to the welfare state, and, on the other hand, intelligence services and some military people seeking a new role after the end of the Cold War' (Bigo 2002: 63-64). In this context, migration and superdiversity are 
increasingly interpreted as a security problem. The prism of security analysis is especially important for politicians, for national and local police organizations, the military police, customs officers, border patrols, secret services, armies, judges, some social services (health care, hospitals, schools), private corporations (bank analysts, providers of technology surveillance, private policing), many journalists (especially from television and the more sensationalist newspapers), and a significant fraction of general public opinion, especially but not only among those attracted to 'law and order'.... The professionals in charge of the management of risk and fear especially transfer the legitimacy they gain from struggles against terrorists, criminals, spies, and counterfeiters toward other targets, most notably transnational political activists, people crossing borders, or people born in the country but with foreign parents (Bigo ibid).

And while the development of new communication technologies has major implications for the maintenance and development of diasporic networks and other types of collectivity (Blommaert and Rampton 2011: 4; Tall 2004), it obviously also plays a major role in surveillance. Observers note that superdiversity presents a major challenge to the traditional forms of social classification with which states and institutions monitor their populations. Scholars argue that instead of relying on essentialist identity categories, research should focus on practices. But with 'transactional surveillance', digital technologies overcome these problems:

[s]ubjects... are very active consuming, swiping credit cards, walking streets, phoning. These activities and transactions are an immediate interaction with and through technology. The interaction creates data that are used to govern subjects and their activities... As Amoore and de Goede state in their exploration of the increasing importance of transactions for security practice and its political implications: '[T]ransactions people make are, quite literally, taken to be traces of daily life, they are conceived as a way of mapping, visualising and recognising bodies in movement' (2008: 176). Ruppert and Savage speak of transactional governance (2011). While traditional data sources engage subjects as identities or fixed populations, transactional governance derives information directly from the interactions and transactions. 'Subjectivity or identity is less an issue and instead associations and correlations in conduct are deemed more empirical and descriptive than subjective and meaningful' (Ruppert 2011: 228). Transactional governance decentres subjects into transactions: what matters is not subjects with opinions or identities but transactions that take place. It is a mode of governing that seeks to quickly adapt delivery of services, control and coercion to changing behaviours deriving and processing information directly from the everyday 'doings' of people. Transactional surveillance is increasingly important in security practice (Huysmans 2014: 166-67).

All this has at least three implications. First, it changes our understanding of the light-weight informational emptiness of phatic communication. Velghe gives a glimpse of this when she describes the jealous boyfriend's suspicion of Lisa's text messaging and the rows that her phatic practices generate, but this can be massively scaled up to security 
surveillance organisations like the NSA and GCHQ, which after all, only process the metadata in our emails - who they are to and what the subject header says-not the contents of the messages themselves. The afterlife of any electronic text, phatic or otherwise, can be very different from its producer's initial intentions (Blommaert 2001) and in social media, the problems are especially acute. Second and more briefly, the temptation to look for conviviality in contemporary superdiversity-to dwell on creative translingual sociability or polylingual business-oriented improvisation-needs to be tempered by attention to fear, unease and their systematic cultivation as modes of control (Khan 2014). And following on from this, third, it is important to ensure that sociolinguists' theoretical attraction to Bakhtin is balanced by an extended engagement with Foucault, who remains a central figure in contemporary studies of security. With heteroglossia and the carnivalesque, Bakhtin speaks straight to the interests of sociolinguistics, but with 'governmentality' as a capillary web of small-scale practices that deliberately 'attempt to shape conduct in certain ways in relation to certain objectives', Foucault can too (Rose 1999: 4; Foucault 1978/2003; Rampton 2014).

\section{NOTES}

1 'a special class of quite conventionalised utterances, lexicalisations whose controlling purpose is to give praise, blame, thanks, support, affection or show gratitude, disapproval, dislike, sympathy, or greet, say farewell and so forth. Part of the force of these speech acts comes from the feelings they directly index; little of the force derives from the semantic content of the words' (Goffman 1981: 20-21).
2 Indeed, elaborating like, for example Levinson 1988 or Irvine 1996, it would be worth exploring the extent to which Goffman's later work on footing and participation frameworks could be extended in a unified analysis of 'likes' and 'sharing', with, for example, the distinction between virality and memicity connecting with Goffman's account of 'responses' and 'replies' (Goffman 1981).

\section{REFERENGES}

Amoore, Louise and Marieke de Goede. 2008. Transactions after 9/11: The banal face of the preemptive strike. Transactions of the Institute of British Geographers 33 (2): 173-85.

Arnaut, Karel. 2012. Super-diversity: Elements of an emerging perspective. Diversities 14 (2): 1-16.

Back, Les. 1996. New Ethnicities and Urban Culture. London: UCL Press.

Bakhtin, Mikhail. 1987. The Dialogic Imagination. Austin: Texas University Press.

Bauman, Richard and Charles L. Briggs. 1990. Poetics and performance as critical perspectives on language and social life. Annual Review of Anthropology 19: 59-88.

Bigo, Didier. 2002. Security and immigration: Toward a critique of the governmentality of unease. Alternatives: Global, Local, Political 27: 63-92.

Blommaert, Jan and Ben Rampton. 2011. Language and superdiversity: A position paper. Working Papers in Urban Language and Literacies, Paper 70. London: King's College Centre for Language Discourse \& Communication. < https:// www.academia.edu/6356809/WP70_ Blommaert_and_Rampton_2011. Language_and_superdiversity_A_ position_paper $>$.

Blommaert, Jan. 2001. Context is/as critique. Critique of Anthropology 21 (1): 13-32.

Blommaert, Jan. 2005. Discourse: A Critical Introduction. Cambridge: Cambridge University Press. 
Blommaert, Jan. 2013. Ethnography, Superdiversity and Linguistic Landscapes: Chronicles of Complexity. Bristol: Multilingual Matters.

Crystal, David. 2008. A Dictionary of Linguistics and Phonetics. Oxford: Blackwell.

Eley, Louise. 2015. A micro-ecology of language in multi-ethnic Frankfurt: The linguistic ethnography of a barbershop. Working Papers in Urban Language E Literacies, Paper 155. London: King's College Centre for Language Discourse \& Communication. <https://www.academia. edu/11365690/WP155_Eley_2015._A_ microecology_of_language_in_multiethnic_Frankfurt_The_linguistic_ ethnography_of_a barbershop>

Foucault, Michel. 1978/2003.

Governmentality. In Paul Rabinow and Nikolas Rose (eds). The Essential Foucault: Selections from Essential Works of Foucault 1954-1984. New York: The New Press. 229-245.

Gilroy, Paul. 2006. Multiculture in times of war: An inaugural lecture given at the London School of Economics. Critical Quarterly 48 (4): 27-45.

Goffman, Erving. 1963. Stigma: Notes on the Management of Spoiled Identity. Harmondsworth: Penguin.

Goffman, Erving. 1981. Forms of Talk. Oxford: Blackwell.

Harris, Roxy and Ben Rampton. 2009. Ethnicities without guarantees: An empirical approach. In Margaret Wetherell (ed). Identity in the $21^{\text {st }}$ Century: New Trends in Changing Times. Basingstoke: Palgrave. 95-119.

Hewitt, Roger. 1986. White Talk, Black Talk. Cambridge: Cambridge University Press.

Huysmans, Jef. 2014. Security Unbound. London: Routledge.

Irvine, Judith T. 1996. Shadow conversations: The indeterminacy of participant roles. In Michael Silverstein and Greg Urban (eds). Natural Histories of Discourse. Chicago: University of Chicago Press. 131-59.

Khan, Kamran. 2014. Citizenship, securitization and suspicion in UK ESOL policy. Working Papers in Urban Language and Literacies, Paper 130. London:
King's College Centre for Language Discourse \& Communication. < https:// www.academia.edu/7517562/WP130 Khan_2014._Citizenship_securitization_ and_suspicion_in_UK_ESOL_policy>

Leech, Geoffrey. $1 \overline{9} 8 \overline{1}$. Semantics: The Study of Meaning. Second Edition. Harmondsworth: Pelican.

Levinson, Stephen. 1983. Pragmatics. Cambridge: Cambridge University Press. Levinson, Stephen. 1988. Putting linguistics on a proper footing: Explorations in Goffman's concepts of participation. In Paul Drew and Anthony Wootton (eds). Erving Goffman: Exploring the Interaction Order. Oxford: Polity Press. 161-227.

Rampton, Ben. 1995. Crossing: Language and Ethnicity Among Adolescents. London: Longman. (2nd Edition 2005: St Jerome Press.) <http://www.kcl.ac.uk/sspp/ departments/education/research/ldc/ publications/Crossing.aspx >

Rampton, Ben. 2014. Gumperz and governmentality in the 21 st century: Interaction, power and subjectivity. Working Papers in Urban Language and Literacies, Paper 136. London: King's College Centre for Language Discourse \& Communication. < https:/www.academia. edu/8114068/WP136_Rampton_2014. Gumperz_and_governmentality_in_ the_21st_century_Interaction_power_ and_subjectivity>

Rampton, Ben, Janet Maybin, and Celia Roberts. 2014. Methodological foundations in linguistic ethnography. Working Papers in Urban Language and Literacies, Paper 125. London: King's College Centre for Language Discourse \& Communication. <https://www.academia. edu/6155510/WP125 Rampton_Maybin and Roberts 2014. Methodological foundations_in_linguistic_ethnography> Rose, Nikolas. 1999. The Power of Freedom. Cambridge: Cambridge University Press.

Ruppert, Evelyn. 2011. Population objects: Interpassive subjects. Sociology 45 (2): 218-33.

Ruppert, Evelyn and Mike Savage. 2011. Transactional politics. Sociological Review 59 (2): 73-92. 
Scollon, Ron and Suzie Wong Scollon. 2004. Nexus Analysis: Discourse and the Emerging. Internet. London: Routledge.

Tall, Serigne Mansour. 2004. Senegalese émigrés: New information and communication technologies. Review of African Political Economy 99: 31-48.

Vertovec, Steven. 2007. New Complexities of Cohesion in Britain: Superdiversity, Transnationalism and Civil-Integration. University of Oxford: COMPAS.
Wetherell, Margaret. 2009. Introduction: Negotiating liveable lives: Identity and intelligibility in contemporary Britain. Identity in the $21^{\text {st }}$ Century: New Trends in Changing Times. Basingstoke: Palgrave. 1-21.

Wise, Amanda and Selvaraj Velayutham. 2014. Conviviality in everyday multiculturalism: Some brief comparisons between Singapore and Sydney. European Journal of Cultural Studies 17 (4): 406-430. 